Voix et Images

voixetimages

\title{
Yves Beauchemin, en toute simplicité
}

\section{Présentation}

\section{Yves Lacroix}

Volume 12, numéro 3 (36), printemps 1987

Yves Beauchemin

URI : https://id.erudit.org/iderudit/200650ar

DOI : https://doi.org/10.7202/200650ar

Aller au sommaire du numéro

Éditeur(s)

Université du Québec à Montréal

ISSN

0318-9201 (imprimé)

1705-933X (numérique)

Découvrir la revue

Citer ce document

Lacroix, Y. (1987). Yves Beauchemin, en toute simplicité : présentation. Voix et Images, 12(3), 358-358. https://doi.org/10.7202/200650ar d'utilisation que vous pouvez consulter en ligne.

https://apropos.erudit.org/fr/usagers/politique-dutilisation/ 


\section{Yves Beauchemin, en toute simplicité}

\section{Présentation}

\section{par Yves Lacroix, Université du Québec à Montréal}

La popularité phénoménale du Matou - si non prévisible, en dépit du succès notable de l'Enfirouapé, du moins préparée par l'auteur et son éditeur - a paradoxalement occulté ses qualités littéraires. Paru en avril, il allait constituer une excellente lecture de vacances, la critique lui en reconnaissait les qualités «américaines» d'accessibilité et d'efficacité. Par accessibilité nous entendons une correction et une transparence de l'énonciation, une discrétion à laquelle le romancier prétend lui-même ostensiblement. Par efficacité nous désignons d'une part la rapidité narrative, les surprises constantes d'un roman picaresque, la démesure caricaturale des personnages, exception faite du couple focalisateur Élise/Florent; d'autre part l'optimisme d'un héros triomphant et l'humour d'un narrateur qui ont scotomisé l'univers paranoïde dans lequel s'agitaient les protagonistes. En d'autres mots, de l'auteur du Matou on a surtout célébré les qualités de conteur dont les lecteurs-spectateurs et le romancier lui-même semblent avoir retrouvé l'essentiel dans les adaptations télévisuelle et cinématographique. Si nous avons voulu faire état de cette réalité, c'est surtout le texte littéraire qu'ont choisi d'interroger deux collaborateurs, soit "le statut sémiologique des personnages», soit le palimpseste autobiographique de l'écrivain Beauchemin.

Conséquence de réticences différemment motivées de l'auteur et de l'éditeur, nous n'avons pu obtenir le droit de publier un extrait du prochain roman, ainsi que nous l'aurions souhaité. 